\title{
EDUCAÇÃO A DISTÂNCIA NAS ESCOLAS DE GOVERNO BRASILEIRAS: A PRODUÇÃO ACADÊMICA NO CAMPO DA EDUCAÇÃO
}

\author{
Claudia Regina Castellano Losso \\ Martha Kaschny Borges \\ Universidade Estadual de Santa Catarina - UDESC (Brasil)
}

\begin{abstract}
Resumo. O artigo apresenta um mapeamento da produção acadêmica sobre educação a distância (EaD) e escolas de governo (EG) no campo da educação. EGs são instituições públicas governamentais brasileiras instituídas a partir da Constituição de 1988, que visam qualificar o serviço público no atendimento às demandas da sociedade de forma eficiente e eficaz. Para promover o desempenho de competências, ofertam cursos presenciais e a distância para formação e capacitação do servidor. Educação a distância tem sido utilizada pelas escolas por ser uma modalidade de ensino de baixo custo e alta capilaridade. $\mathrm{Na}$ fundamentação, foram analisados conceitos sobre desenvolvimento de competências, educação corporativa governamental e educação a distância. A revisão bibliográfica foi realizada em 2017 em três bases de dados: Banco de Teses da Capes, Revista do Serviço Público e Google Scholar. Com os descritores "escola de governo" e "EaD", selecionamos quatro trabalhos relacionados à educação. Os resultados comprovam a escassez de produção sobre o tema no campo da educação, bem como a importância do incentivo e do desenvolvimento de pesquisas nesse campo. Diante da grandiosidade do Brasil em relação ao número de servidores públicos, ainda há muito a ser percorrido, e experiências em EaD devem ser compartilhadas para alimentar a rede de escolas de forma acadêmica, teórica, no que diz respeito às abordagens, metodologias e práticas.
\end{abstract}

Palavras-chave: Educação a distância, escola de governo, desenvolvimento de competências, revisão bibliográfica.

\section{DISTANCE EDUCATION IN BRAZILIAN GOVERNMENT SCHOOLS: ACADEMIC PRODUCTION IN THE FIELD OF EDUCATION}

\begin{abstract}
The article presents a mapping of the academic production on learning and Schools of Government in the field of education. Brazilian government schools are public governmental institutions established since the 1988 Constitution, which aim to qualify the public service in solving the demands of society in an efficient and effective manner. To promote the performance of competencies they offer distance courses for training and qualification of the server. Distance education has been used by schools because it is a modality of teaching of low cost and high capillarity. In order to justify, we have brought concepts about skills development, corporate education and distance education. The bibliographic review was carried out in 2017 in three databases: Capes Bank of Theses, Public Service Magazine and Google Scholar. In partnership with "school of Government" and "EaD" we selected four works related to education. The results confirm the lack of production on the subject in the field of education and that research should be encouraged and developed in the schools of government in this field. When faced with the greatness of Brazil in relation to the number of public servants, there is still a long way to go, and experiences in e-learning must be shared to feed the school network in an academic, theoretical way with regard to approaches, methodologies and practices.
\end{abstract}

Keywords: Distance Education, government schools, development of skills, bibliographic review. 


\title{
EDUCACIÓN A DISTANCIA EN LAS ESCUELAS DE GOBIERNO BRASILEÑAS: LA PRODUCCIÓN ACADÉMICA EN EL CAMPO DE LA EDUCACIÓN
}

\begin{abstract}
Resumen. El artículo presenta un mapeo de la producción académica sobre EaD y Escuelas de Gobierno en el campo de la educación. Las escuelas de gobierno brasileñas son instituciones públicas gubernamentales instituidas a partir de la Constitución de 1988, que apuntan a calificar el servicio público en la atención a las demandas de la sociedad de forma eficiente y eficaz. Para promover el desempeño de competencias ofrecen cursos presenciales y a distancia a través de la formación y capacitación del servidor. La educación a distancia ha sido utilizada por las escuelas por ser una modalidad de enseñanza de bajo costo y alta capilaridad. Para fundamentar trabajamos conceptos sobre desarrollo de competencias, educación corporativa gubernamental y educación a distancia. La revisión bibliográfica se realizó en 2017 en tres bases de datos: Banco de Tesis da Capes, Revista del Servicio Público y Google Scholar. Con los descriptores "escuela de gobierno" y "EaD" seleccionamos cuatro trabajos relacionados a la educación. Los resultados demuestran la escasez de producción sobre el tema en el campo de la educación y qué investigaciones deben ser incentivadas y desarrolladas en las escuelas de gobierno en ese campo. Ante la grandiosidad de Brasil en relación al número de servidores públicos aún hay mucho que recorrer y experiencias en $\mathrm{EaD}$ deben ser compartidas para alimentar la red de escuelas de forma académica, teórica en lo que se refiere a los enfoques, metodologías y prácticas.
\end{abstract}

Palabras clave: Educación a distancia, escuela de gobierno, desarrollo de competencias, revisión bibliográfica.

\section{Introdução}

As demandas da sociedade para a eficácia e efetividade dos serviços públicos são reflexos de sociedades democráticas, que exigem uma melhor qualidade dos servidores e funcionários em muitos aspectos. A necessidade de um ótimo atendimento ao público, bem como análise rápida e resolução eficaz de problemas de atividadesmeio, segurança das informações, transparência ou melhoria dos processos internos de uma instituição governamental, em qualquer esfera de poder, demanda profissionais aptos ao serviço público de forma integral.

A formação do servidor público para a melhoria dos serviços aos cidadãos se tornou uma preocupação atual e mundial, num processo em franca expansão. Escolas especializadas para essa finalidade foram criadas e algumas delas servem de modelo para muitas outras, como a conceituada Ècole Nationale d'Administration (l'ENA) da França, da qual se originaram vários grandes nomes da política internacional e também gestores públicos, como Charles de Gaulle, François Mitterand, entre outros. A escola francesa é ainda a melhor referência na formação de servidores públicos, principalmente para a alta gestão.

Atualmente, muitos países criaram suas escolas de governo (EG) em sintonia com diretrizes mundiais para essa finalidade. Algumas dessas orientações são elaboradas pela Organização para a Cooperação e Desenvolvimento Econômico (OCDE), organismo que busca promover políticas que melhorem o bem-estar econômico e social das pessoas em todo o mundo.

Durante o processo de redemocratização do Brasil, mais precisamente em 1986, a Escola Nacional de Administração (ENAP) foi criada, e a partir de sua existência e suas atividades iniciou-se um movimento de organização legal para implementação de 
EGs em outros âmbitos da esfera pública. Em 1988, a Constituição Federal do Brasil (art. 39, § $2^{\circ}$ ) passou a determinar que a União, os Estados e o Distrito Federal mantenham EGs em todo o território nacional.

$\S 2^{\circ}$ A União, os Estados e o Distrito Federal manterão escolas de governo para a formação e o aperfeiçoamento dos servidores públicos, constituindose a participação nos cursos um dos requisitos para a promoção na carreira, facultada, para isso, a celebração de convênios ou contratos entre os entes federados. (Brasil, 1988, s. p.).

As EGs, portanto, surgem para que o Estado cumpra os princípios basilares de seus objetivos maiores de desenvolvimento e de progresso, atendendo as demandas da sociedade com gestores e servidores públicos preparados, com conhecimentos, habilidades e atitudes coerentes com a função pública, para executar atividades de forma eficiente. A formação de quadros aptos ao serviço público não se restringe somente ao concurso de acesso ao cargo público.

As escolas em funcionamento no Brasil oferecem cursos livres, de graduação e pós-graduação, de acordo com a sua capacidade e estrutura, que podem ser presenciais e a distância, visando à qualificação do servidor público de acordo com as estratégias de governo vigente. A educação a distância $(\mathrm{EaD})$ é um fenômeno educacional produto do avanço das tecnologias da comunicação e informação, e se transformou numa modalidade de ensino muito solicitada no Brasil, justificada principalmente pelas grandes dimensões geográficas do território nacional.

Poucas pesquisas tratam do tema da $\mathrm{EaD}$ especificamente relacionada às EGs; nesse contexto, o presente artigo é apresentado, trazendo uma revisão da literatura no que tange à produção acadêmica realizada no Brasil, no campo específico da educação.

\section{A educação corporativa e as EGs}

A preocupação em oferecer um serviço público eficaz e eficiente, em dar respostas rápidas aos problemas sociais, para muitas nações só é possível por meio de capacitação e formação, e tem se tornado um desafio constante no Brasil. Não basta apenas a execução de ações planejadas em políticas públicas para solução de problemas do país. Capacitar agentes públicos tornou-se essencial em estados democráticos, pois em momentos de renovação política as instituições públicas se preservam, mesmo quando há descontinuidade administrativa. Segundo Bittencourt e Zouain (2010), em eventos que discutem a reforma do Estado,

Recomenda-se aparelhamento burocrático estável - a salvo de descontinuidades administrativas - competente, devidamente preparado para adoção de inovações organizacionais e de modernas técnicas de gestão, habilitado a formular, a executar, a monitorar e a avaliar políticas públicas capazes de responder a desafios contemporâneos (p. 77).

Nesse contexto, as EGs ganham um importante papel, com funções e características específicas, de qualificar e profissionalizar o servidor público, contribuindo diretamente para a melhoria dos serviços oferecidos. Isso não significa a ausência de iniciativas anteriores de qualificar o servidor público por meio de capacitação, mas, como será visto adiante, foi uma trajetória construída ao longo do tempo, tendo em vista as necessidades e os objetivos das instituições, e o momento histórico e político vigente. 
As EGs no Brasil seguem um alinhamento político pedagógico semelhante entre elas, devido à finalidade em comum. Isso porque tratam da formação de profissionais com trajetórias de vida pessoal e profissional consolidada, mas em constante evolução. Trabalham na perspectiva da Andragogia, ou seja, da educação de adultos.

A motivação dos servidores para a participação em cursos varia, pois nem sempre a ascensão profissional está atrelada a um maior nível de escolaridade. As formações e capacitações contribuem para a melhoria de seu trabalho ou crescimento pessoal, e podem agregar valor às suas atividades e ao seu desempenho. Outro fator incentivador é a progressão funcional na carreira, concretizada pela participação efetiva em cursos de capacitação.

Independentemente da instituição de origem, muitos servidores e funcionários públicos procuram a complementação de estudo de que necessitam, seja para melhoria financeira, seja para outros fins. Essa busca anteriormente se concentrava na iniciativa privada ou em universidades; entretanto, após a implementação da Política Nacional de Desenvolvimento de Pessoal (PNDP) pelos órgãos e pelas entidades da administração pública federal direta, autárquica e fundacional, em 2006, as EGs passam a ser priorizadas como instâncias de ensino no serviço público.

As conexões entre instituições com o mesmo objetivo em comum propiciam uma troca de informações e o compartilhamento de conhecimentos que podem auxiliar na composição de projetos de cursos, de metodologias inovadoras para auxílio na aprendizagem, bem como encurtar caminhos com as boas práticas das instituições.

Conforme Alperstedt (2001, p. 150), as empresas podem aprimorar os seus processos a partir de suas próprias experiências, e também por meio do benchmarking, um método de aprendizado com empresas que são reconhecidas como portadoras das melhores práticas em produtos, serviços e processos, com a finalidade de melhoria organizacional que busca informações sucessivas do mercado e da concorrência.

Nesse sentido, aprendizagem organizacional em instituições públicas passa a ser um termo relevante, e os processos para se conquistar patamares elevados de amadurecimento nesse aspecto acontecem por meio da educação corporativa governamental.

\section{Desenvolvimento de Competências na Educação Corporativa Governamental}

Na PNDP, a capacitação é entendida como “... um processo permanente e deliberado de aprendizagem, com o propósito de contribuir para o desenvolvimento de competências institucionais, por meio do desenvolvimento de competências individuais" (Brasil, Decreto 5707/2006, art. $2^{\circ}$, inciso I). A partir dessa definição, as competências a serem desenvolvidas em cada servidor estão associadas com as necessidades e os objetivos da organização.

As competências individuais necessárias para que um indivíduo possa conduzir de forma assertiva suas funções em qualquer atividade são compostas pelas seguintes dimensões: conhecimentos, habilidades e atitudes, mais comumente denominadas como CHA. Assim sendo, para que se desenvolvam as competências num indivíduo, as três dimensões do CHA precisam estar inter-relacionadas.

De acordo com Eboli (2004, p. 53), cada dimensão tem sua especificidade, conforme a Figura 1: 


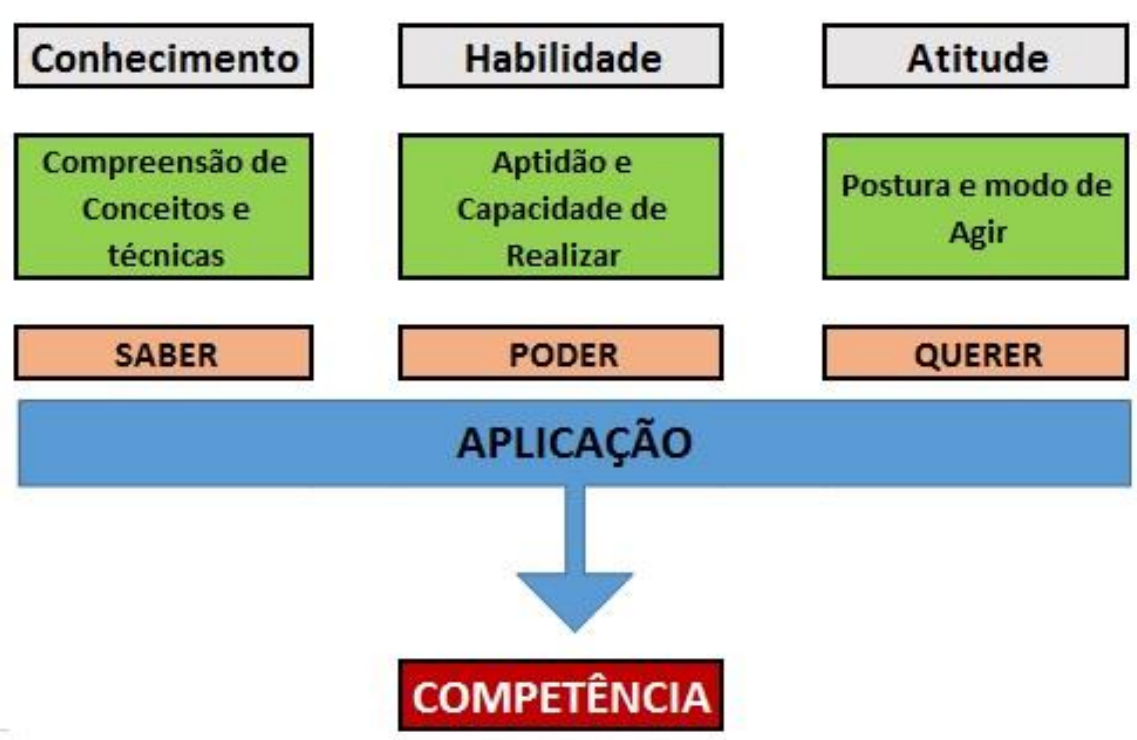

Figura 1. Quadro sintético sobre o CHA Nota: Fonte: Adaptado de Eboli (2004)

Ainda, segundo a autora, as dimensões compostas pelo CHA podem ser traduzidas da seguinte maneira: conhecimento está relacionado à transformação e significação das informações recebidas, que deve dar condições ao indivíduo "saber o que e porque fazer"; habilidade está relacionada com a técnica, possibilitando uma ação reflexiva de "saber como fazer"; atitude é a vontade, o desejo de realizar, a determinação em "saber fazer acontecer" (Eboli, 2004, p.53). A conjunção das três dimensões possibilita ao indivíduo ter condições para ir além de executar funções, mas ter consciência de suas aptidões cognitivas para assumir suas responsabilidades com total competência. Somente com o desenvolvimento de competências dos servidores públicos haverá serviços melhores entregues à sociedade.

De forma geral, as instituições governamentais buscam o desenvolvimento das pessoas por meio de ações planejadas nos departamentos setoriais, por exemplo, o de recursos humanos, mais conhecido pela abreviatura RH. Esse setor, com as novas tendências em administração pública, vem se transformando em uma área de Gestão de Pessoas, ampliando a simples função de administrar a vida funcional dos servidores para uma intenção mais global, voltada ao desenvolvimento de competências de acordo com o CHA. A preocupação em identificar as lacunas de capacitação é uma prática constante do setor de RH das instituições, públicas ou privadas. Conforme Pacheco (2002), o setor responsável promovia um processo denominado LNT, ou seja,

... "levantamento de necessidades de treinamento", na qual o setor de RH "fazia circular", entre os funcionários, uma enquete sobre suas demandas individuais por cursos, depois consolidadas em listas de "demandas por treinamento da organização", em que as maiores prioridades correspondiam aos temas de maior incidência das demandas individuais. (Pacheco, 2002, p. 78).

Esse processo era totalmente individualizado, tomando por necessidade um conhecimento que talvez não fosse estratégico para a instituição, podendo até mesmo resultar em demandas originadas por razões particulares. 
Atualmente as instituições procuram formações e capacitações que estejam alinhadas aos objetivos estratégicos da instituição, visando a melhoria da gestão, alterando esse formato de processo de busca do setor de RH ou Gestão de Pessoas. A decisão sobre o tipo de qualificação do serviço público tem tomado outra direção. Apesar de essa não ser a realidade de todas as instituições públicas, é um caminho a se seguir.

Essa visão anteriormente delineada sobre as necessidades de treinamento teve sua base alicerçada no modelo capitalista de produção Taylorista-Fordista, relacionado ao tradicional Treinamento e Desenvolvimento (T\&D). Era um paradigma que atendia um contexto histórico e político, mas que foi migrando para um novo modelo, instituído pelas universidades corporativas. No universo das instituições públicas, a sociedade exige um novo servidor público, qualificado e profissional, um agente público com competências para uma nova sociedade.

O conceito "profissionalismo" foi muito discutido pelo intelectual francês Guy Le Boterf (2003), diante de um contexto de sério desemprego na França dos anos 1970, que desencadeou uma exigência pelas empresas de profissionais mais preparados para atender a crescente competitividade do mercado, com competências para satisfazer essas demandas. $\mathrm{O}$ autor, estudioso do mundo do trabalho, ainda destaca que, com os avanços tecnológicos a partir dos anos 1980, se configuraram novas formas de organização do trabalho que forçaram os indivíduos a se prepararem para uma fase de mobilidade profissional. Nesse sentido, passou a não bastar apenas ser qualificado, sendo necessário, mais do que isso, ser competente. A respeito do tema, Le Bouterf esclarece que:

... qualificação se reveste de um caráter convencional. Quando a qualificação se reduz a diplomas de formação inicial, isso não significa que a pessoa saiba agir com competência. Significa, antes, que ela dispõe de certos recursos com os quais pode construir competências. (2003, p. 21).

Qualificação, para Le Bouterf, é “... uma construção social, com sistemas de classificação e realizadas em convenções coletivas.” (Le Bouterf, 2003, p. 21). Seguindo essa linha de pensamento, o desenvolvimento de competências pode ampliar o escopo das qualificações de um indivíduo, e isso se dará, no âmbito da administração pública, por meio de capacitações e formações.

Pacheco (2002) busca elencar prioridades para as ações de capacitação em organizações, seguindo uma metodologia que pode ser representada da seguinte maneira: a) observar o planejamento estratégico da instituição; b) desdobrar as competências requeridas para seus quadros; c) mapear as competências existentes, comparando-as com as necessárias; d) identificar as lacunas de competências; e e) definir quais competências podem ser desenvolvidas por um programa de capacitação.

Algumas estratégias para planejamento das capacitações nas EGs passam pelo benchmarking, como já foi mencionado anteriormente, bem como a antecipação de tendências na área da administração pública. Essas tendências passam pelo acompanhamento da atualização na legislação em todas as áreas de atuação dos governos que possam ser atendidas pelas escolas, e dessa forma anteverem as necessidades de formação ou capacitação. 
Outra estratégia adotada é identificar os casos de sucesso, de forma a conhecer as boas práticas realizadas em outras instituições e instâncias governamentais, como fonte de inspiração para produção de novos conhecimentos.

Todas as medidas acima explicitadas para desenvolver as competências dos profissionais das instituições elevam o nível de profissionalismo que a sociedade exige dos serviços públicos. A discussão sobre profissionalismo em qualquer organização, para Guy Le Bouterf, está em como "saber mobilizar" as competências para o sucesso. Para ele, a competência não é um estado, e sim um processo de saber agir.

L'opérateur compétent est celui qui est capable de mobiliser, de mettre en œuvre de façon efficace les différentes fonctions d'un système où interviennent des ressources aussi diverses que des opérations de raisonnement, des connaissances, des activations de la mémoire, des évaluations, des capacités relationnelles ou des schémas comportementaux. Cette alchimie reste encore largement une terra incognita. (Le Boterf, 1994, p. 43).

No campo da educação, as competências são discutidas a partir do trabalho desenvolvido por Phillipe Perrenoud, sociólogo francês. O professor é a figura central da discussão, e Perrenoud busca em Le Bouterf, seu contemporâneo, a inspiração em seus pensamentos.

Autor do livro As 10 competências para ensinar, Perrenoud (2000) afirma que competência é uma capacidade de mobilizar diversos recursos cognitivos para enfrentar um tipo de situação, e descreve quatro aspectos inspirados na visão de Le Bouterf:

1. As competências não são elas mesmas fazeres, savoir-faire ou atitudes, mas mobilizam, integram e orquestram tais recursos; 2. Essa mobilização só é pertinente em situação, sendo cada situação singular mesmo que se possa tratá-la em analogia com outras já encontradas; 3. O exercício da competência passa por situações mentais complexas subtendidas por esquemas de pensamento que permitem determinar (mais menos consciente e rapidamente) e realizar (de modo mais ou menos eficaz) uma ação relativamente adaptada à situação; 4. As competências tradicionais constroem-se em formação, mas também ao saber da navegação diária de um professor, de uma situação de trabalho à outra. (Perrenoud, 2000, p. 15)

As competências de um professor de cursos a distância são identificadas na prática, já que essa modalidade de ensino demanda, além do conhecimento específico sobre a matéria, capacidades cognitivas para o uso das tecnologias na educação. $\mathrm{O}$ professor precisa planejar atividades síncronas e assíncronas mediadas pela tecnologia digital, e compreender que seu aluno também aprende da mesma forma, ou seja, mediado pelas tecnologias.

Essas tecnologias têm papel fundamental na modernização da gestão pública, criando sistemas, melhorando processos e possibilitando novas ferramentas de trabalho. Ainda que os indivíduos tenham que se preparar para as profissões do futuro, o profissionalismo e as competências individuais nunca serão substituídos pela automação. Segundo Le Bouterf (2003), “... cada indivíduo competente é único e não é intercambiável. Sua competência é subjetiva e não pode ser informatizada.” (p. 22). Para essa afirmação, cita Pierre Lèvy quando este diz que o indivíduo é "irredutível à automatização", pois carrega em si laços sociais, relacionais. 
O debate sobre a noção de competência tem várias origens e aplicações, não se encerra na atualidade e está sempre relacionado ao desempenho, ou a uma preocupação acerca da qualificação para empregabilidade. Sintetizando, competência é um saber agir responsável e que é reconhecido pelos outros (Fleury e Fleury, 2001). Implica saber como mobilizar, integrar e transferir os conhecimentos, os recursos e as habilidades num contexto profissional determinado. Portanto, a articulação do emprego do CHA, quando mobilizado de maneira inter-relacionada em um contexto para resolver um problema, uma situação, um imprevisto ou uma novidade, superá-los ou lidar com eles, forma a competência de um indivíduo.

Competência não se aprende em sala de aula, mas num ambiente de aprendizagem propício para novos conhecimentos. Com trocas e compartilhamentos de ideias, ela emerge como uma necessidade na resolução de problemas. Assim, o desenvolvimento de competências nas organizações públicas passa pela educação, pela capacitação, pela formação.

\section{Educação a distância nas organizações públicas}

A necessidade de formatação de cursos de capacitação, de formação ou aperfeiçoamento nas organizações tem dois grandes objetivos: tornar as empresas ou organizações mais competitivas no mercado e melhorar os processos, finalísticos ou estratégicos, tornando-os mais eficientes, por meio de ofertas educativas aos seus funcionários ou colaboradores. Nas instituições públicas, a melhora na eficiência e eficácia dos serviços pode ser considerada como um termo comparável ao da competitividade. Nessa busca, a $\mathrm{EaD}$ tem sido apropriada como uma alternativa de ensino pelas instituições públicas, e está cada vez mais presente no ambiente corporativo.

Essa modalidade de ensino é vista como uma excelente oportunidade de disseminação do conhecimento, possibilitando a capacitação do corpo funcional em grande escala pela não limitação geográfica, e fácil acesso aos conteúdos.

\section{Ambientes virtuais de aprendizagem (AVA) e a aprendizagem on-line}

A educação a distância em ambientes virtuais, também denominada $\mathrm{EaD}, e$ learning, ou educação on-line, é o nome dessa transformação em que a utilização de novas tecnologias de multimídia e da internet tem o objetivo de melhorar a qualidade da aprendizagem, facilitando o acesso a recursos e serviços, assim como de possibilitar trocas de informação e o trabalho colaborativo. Basicamente, é o uso de ferramentas digitais e de tecnologia de suporte à aprendizagem e ao ensino.

As EGs têm utilizado essa modalidade de ensino como forma de atingir seus objetivos e, por essa razão, foram o foco deste artigo, que faz parte de uma pesquisa de tese ainda em andamento. Essa modalidade de ensino pode promover o processo de aprendizagem de forma mais ampla e com uma alta capilaridade na abrangência, alinhando objetivos estratégicos das instituições às necessidades dos alunos/servidores.

A EaD mediada por tecnologias digitais é realizada em ambientes virtuais de aprendizagem (AVA), traduzidos em plataformas digitais, que são desenhados de acordo com as características dos cenários pedagógicos previamente identificados a partir da competência desejada que se pretende alcançar (Gamez, 2011). Esquematicamente, pode-se representar o funcionamento dos cursos $\mathrm{EaD}$ da seguinte maneira: 


\section{Tabela 1}

Processo de concepção de cursos EaD

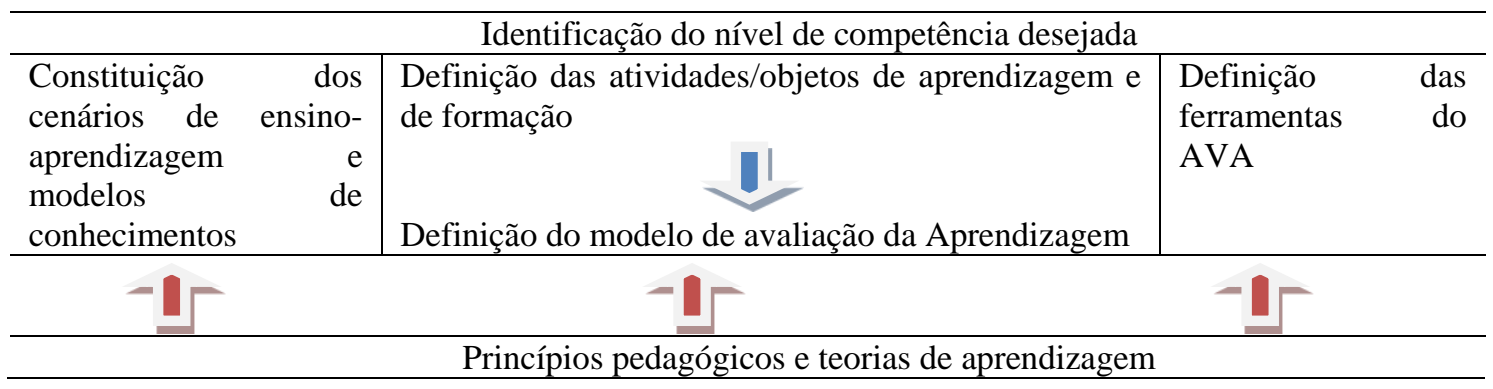

Nota: Fonte: Adaptado de Gamez (2011)

A elaboração de projetos de $\mathrm{EaD}$ não é tarefa fácil. Exige, é claro, além de tecnologias, um eficiente sistema de gerenciamento, produção e disponibilização de conteúdos específicos com embasamento pedagógico e teórico definidos. Imprescindível a participação de uma equipe multidisciplinar, que envolve profissionais de recursos humanos, tutores e professores, e ainda oferecer suporte de profissionais na área de tecnologia educacional, a exemplo de pedagogos, conteudistas, designers instrucionais, revisores, coordenadores de equipe, web designers, webmasters, equipe de gerência e administração de projetos, ilustradores, programadores e analistas. Portanto, para que ocorra um bom projeto em EaD, este deve se sustentar nas tecnologias, nos conteúdos produzidos e na gestão do ambiente, os três elementos fundamentais.

Um ambiente de EaD deve abarcar características básicas, tais como centralização na aprendizagem, bom desenho, interatividade, eficiência e facilidade de acesso. Além disso, depende da eficácia do desenvolvimento de suas cinco etapas distintas do ciclo de produção, que, segundo Cassettari (2001), consistem em: planejamento, design, produção, implantação e avaliação.

Para serem viáveis, os ambientes virtuais de $\mathrm{EaD}$ precisam estar inseridos em plataformas virtuais, com linguagem apropriada e design específico, congregando todas as funcionalidades.

\section{Sistema de Gestão de Aprendizagem ou Learning Management System (LMS)}

Todo ambiente de $\mathrm{EaD}$ precisa ser gerenciado de forma eficaz e constante. $\mathrm{O}$ Sistema de Gerenciamento de Cursos (SGC) - em inglês, Learning Management System (LMS), também chamado de Sistema de Gestão de Conteúdo de Aprendizagem ou Learning Management Content System (LMCS) - disponibilizam uma série de recursos, síncronos e assíncronos, que dão suporte ao processo de aprendizagem, permitindo seu planejamento, sua implementação e sua avaliação. Esses sistemas têm como função principal facilitar a criação, armazenar, reutilizar e refinar cursos. Muitos sistemas de gestão de conteúdo já estão disponíveis, como o Amadeus lms., a plataforma Moodle e o sistema TelEduc. Todos estão em código aberto (open source), com algumas características comuns: a) o registro, a monitoração e o controle das atividades e do acesso dos aprendizes; b) a compatibilidade com as especificações existentes; c) a interatividade; e, d) a gestão dos conteúdos. 
De acordo com Eboli (2012, p. 193), as vantagens para as instituições que têm utilizado o recurso de LMS são várias: diminuição do tempo para treinamentos; redução de infraestrutura física; mensagens consistentes (todos recebem o mesmo conteúdo, apresentados da mesma forma); mensagens customizadas (adequação para diferentes audiências); disponibilização do ambiente a qualquer hora e local; facilidade de inclusão e alteração de conteúdo a qualquer momento; universalidade; construção de comunidades (durante e pós-curso); escala (maior alcance no número de alunos); e disponibilidade de recursos e ferramentas interativas, promovendo várias possibilidades de intervenções pedagógicas.

A grande vantagem desses sistemas é a ampla troca do conhecimento entre os participantes do ambiente, possibilitando a criação de novos conhecimentos. O uso da tecnologia no processo de ensino-aprendizagem dá o suporte necessário para a inteligência coletiva, definida como a soma de competências dos membros de uma equipe para um crescimento maior de todos, facilitado através do uso de redes de computadores e interfaces digitais.

Segundo Lévy (2003, p. 28), a inteligência coletiva é “... uma inteligência distribuída por toda parte, incessantemente valorizada, coordenada em tempo real, que resulta em uma mobilização efetiva das competências." As ferramentas disponibilizadas nos AVAs, como fórum, chat, e-mail, listas de discussão, propiciam a interação, reconhecendo naquele espaço coletivo as habilidades individuais na construção do conhecimento.

Dessa forma, para conhecer a realidade das EGs em relação ao uso da $\mathrm{EaD}$, foi feita a revisão da produção acadêmica no campo de conhecimento da educação em banco de dados de bases científicas e revistas especializadas, conforme descritas a seguir.

\section{Metodologia}

Inserido numa pesquisa de doutorado em andamento, a revisão realizada sobre o tema da EaD em EGs no Brasil no ano de 2017 trouxe subsídios para a análise do cenário. Trata-se de uma pesquisa exploratória e descritiva. É um estudo qualitativo que pode promover uma primeira inserção à temática, apresentando o movimento e desenvolvimento dos conhecimentos produzidos da área, além de identificar tendências, ênfases, escolhas metodológicas e teóricas, por meio de convergências e diferenças detectadas nos trabalhos selecionados.

Procurou-se identificar, por meio de uma revisão sistemática na produção acadêmica, as referências utilizadas nas investigações e produções educacionais, e a natureza dos trabalhos selecionados, além de analisar como o tema da educação on-line ou EaD é abordado na educação corporativa governamental das EGs. Dessa forma, este artigo apresenta uma revisão de literatura nas bases de dados no Banco de Teses da Coordenação de Aperfeiçoamento de Pessoal de Nível Superior (Capes), na Revista do Serviço Público (RSP), publicada pela ENAP, e no Google Scholar.

A coleta dos dados na busca das publicações foi realizada no mês de abril de 2017; para tal, foi utilizado o descritor primário "escola de governo", combinado com o secundário "EaD". Utilizamos o operador lógico "and" entre o primário e o secundário.

Quanto aos critérios de seleção, definimos os seguintes: 
a) estudos publicados a partir do ano de 2010;

b) trabalhos como artigos, resultados de conferências, anais, produção textual e livros;

c) revistas relacionadas à educação e à administração pública;

d) língua portuguesa;

e) documentos com resumos e textos acessíveis on-line.

Concluídas as análises das pesquisas encontradas para a revisão, são apresentados em seguida alguns resultados preliminares.

\section{Resultados}

\section{A busca por pistas - bases de dados}

Trabalhos e pesquisas acadêmicas em torno do tema EaD são importantes no sentido de esclarecerem, entre outros aspectos, quais tipos de metodologias podem ser aplicados, quais teóricos discutem o assunto, quais experiências já foram realizadas, bem como indicam caminhos para se avançar nas produções e discussões dessa temática.

Antes da filtragem dos resultados, num primeiro momento da busca, foram identificados um total de 168 trabalhos, dos quais quatro se encontravam na base de dados da RSP (ENAP), 62 no Google Scholar e 102 no Banco de Teses da Capes.

Para tornar os trabalhos "elegíveis" para esta pesquisa, partiu-se em busca dos resumos, de termos ou indicações que realmente teriam como foco o uso da $\mathrm{EaD}$ nas EGs, o que reduziu drasticamente os resultados, como visto a seguir.

Após o refinamento da busca com uma leitura mais detalhada dos resumos, esta ficou limitada a 27 trabalhos, dos quais três se repetiam em duas bases e tiveram suas duplicatas eliminadas. Desses 24 trabalhos, uma análise mais criteriosa excluiu aqueles que não teriam relação direta com EGs e com a ENAP (pela sua relevância nesse contexto). Desse processo, revelou-se como o tema da EaD relacionada às EGs é pouco explorado no Brasil. Somente restaram sete trabalhos, reduzindo-se a apenas quatro depois de constatada a duplicidade de alguns.

Esquematicamente, o fluxo da revisão pode ser apresentado da seguinte forma: 


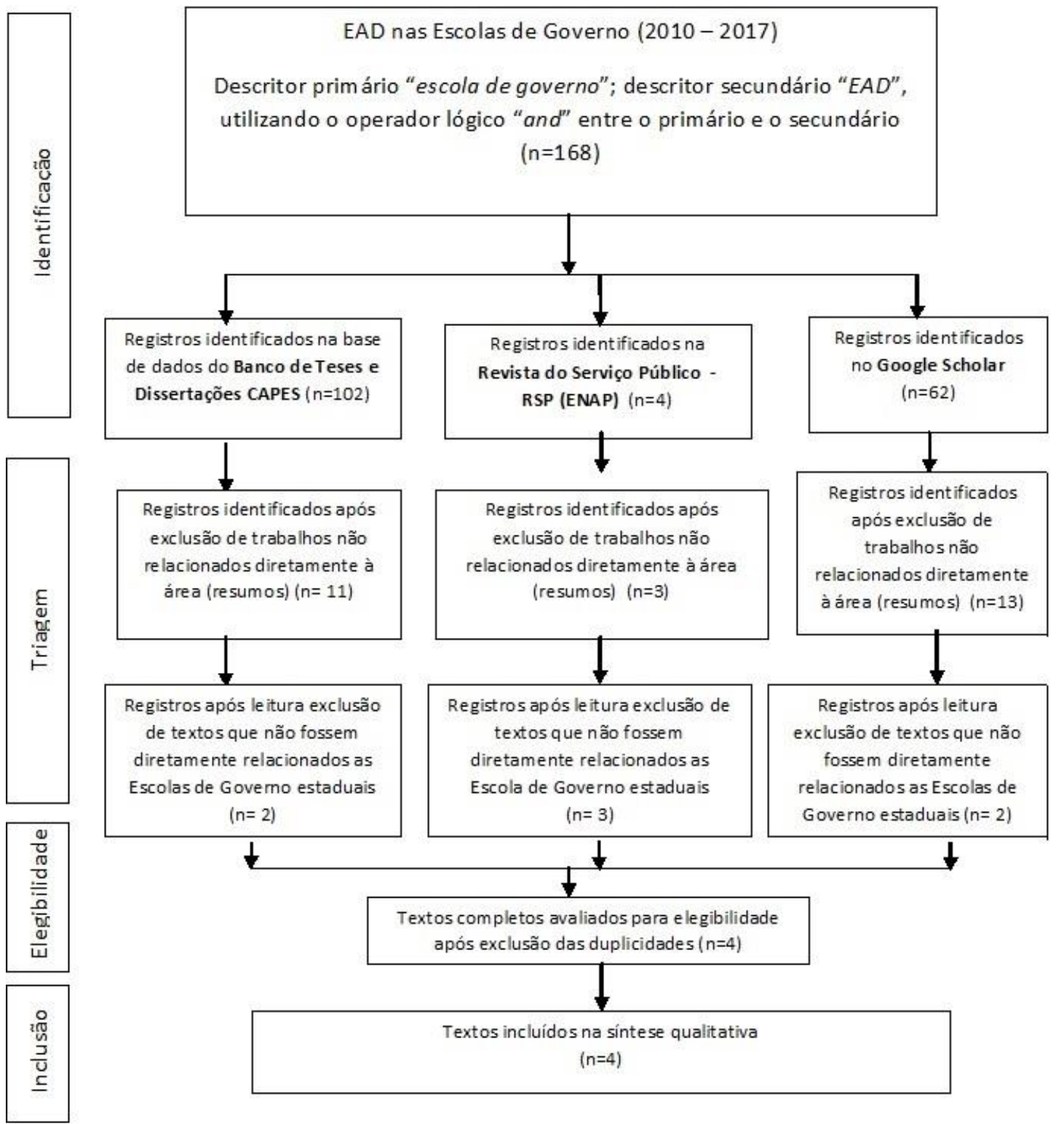

Figura 2. Diagrama de fluxo de inclusão e exclusão dos estudos publicados no Banco de Teses da Capes, na RSP e no Google Scholar

Nota: Fonte: Dados compilados em de Banco de Teses da Capes, RSP e Google Scholar

Em termos de pesquisas consolidadas, foram identificados apenas quatro trabalhos de acordo com os resultados obtidos em relação à origem e ao tipo de trabalho, conforme quadro a seguir:

Tabela 2

Trabalhos elegíveis para a pesquisa

\begin{tabular}{|c|c|c|c|c|}
\hline Ordem & Título & Autor & Tipo & $\begin{array}{l}\text { Base de } \\
\text { dados }\end{array}$ \\
\hline 1 & $\begin{array}{l}\text { Acessibilidade e usabilidade } \\
\text { em curso on-line: um desafio } \\
\text { para as escolas de governo }\end{array}$ & $\begin{array}{l}\text { Simone } \\
\text { Moreira } \\
\text { Oliveira }\end{array}$ & $\begin{array}{l}\text { Dissertação } \\
2016\end{array}$ & Capes \\
\hline
\end{tabular}




\begin{tabular}{|c|c|c|c|c|}
\hline 2 & $\begin{array}{l}\text { O Ensino à Distância da } \\
\text { Escola de Gestão Pública do } \\
\text { Estado do Ceará - EGP } \\
\text { como estratégia de formação } \\
\text { de servidores públicos: uma } \\
\text { avaliação de resultados }\end{array}$ & $\begin{array}{l}\text { Wagner Nery } \\
\text { Moreira } \\
\text { Aguiar }\end{array}$ & $\begin{array}{l}\text { Dissertação } \\
2012\end{array}$ & Capes \\
\hline 3 & $\begin{array}{lll}\text { Ambientes virtuais } & \text { de } \\
\text { aprendizagem: desafios } & \text { de } \\
\text { uma escola de governo } & \end{array}$ & $\begin{array}{l}\text { Andrea Filatro } \\
\text { e Natália Teles } \\
\text { da Mota }\end{array}$ & Artigo 2013 & RSP \\
\hline 4 & 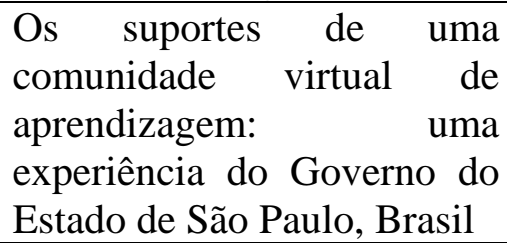 & $\begin{array}{l}\text { Tania Tavares } \\
\text { Silva, Paulo } \\
\text { Dias e José } \\
\text { Armando } \\
\text { Valente }\end{array}$ & Artigo 2013 & RSP \\
\hline
\end{tabular}

Nota: Fonte: As autoras

\section{Análise dos trabalhos}

A dissertação de mestrado de Simone Moreira de Oliveira (2016), intitulada "Acessibilidade e usabilidade em curso on-line: um desafio para as escolas de governo", foi o trabalho mais atual encontrado. Tratou-se de uma pesquisa de caráter qualitativo, com objetivo de analisar as condições de acessibilidade de um curso on-line oferecido por uma EG no Distrito Federal, por meio da percepção de pessoas cegas e de pessoas surdas. A autora afirmou ter utilizado uma concepção filosófica reivindicatória/participatória como base teórica. Foi um estudo de caso em pesquisa participante e realizou uma análise documental, com entrevista semiestruturada e observação. Mesmo com intervenção da pesquisadora na aplicação de melhorias, os sujeitos cegos continuaram a enfrentar dificuldades de acessibilidade e de usabilidade, demonstrando a necessidade de adoção de tecnologias na concepção de AVAs que permitam o acesso a todos de maneira indistinta e efetiva.

A segunda dissertação, de autoria de Wagner Nery Moreira Aguiar, finalizada em 2012, cujo título é "O Ensino à Distância da Escola de Gestão Pública do Estado do Ceará - EGP como estratégia de formação de servidores públicos: uma avaliação de resultados", teve como objetivo avaliar resultados do ensino a distância da Escola de Gestão Pública do Estado do Ceará (EGP). A EGP foi criada em 2009 e possui um Núcleo de Educação a Distância Governamental (@NEDGOV) para as ações em EaD. Para tanto, se apoiou em pesquisa bibliográfica sobre o tema EaD, relacionando-o com educação e trabalho.

O universo da pesquisa se deu em seis cursos oferecidos, nos quais foram analisados dados de índices gerais de aprovação, reprovação, desistência e abandono no ano de 2011, na modalidade EaD. Foi realizada também uma pesquisa com os alunos egressos desses seis cursos, para identificar o desempenho profissional após a participação nos referidos cursos. De modo geral, mesmo com elevados índices de evasão nos cursos, os participantes relataram uma melhora no desempenho profissional.

Nesse trabalho, foi identificada a relevância dada à relação entre o desenvolvimento de desempenho e a aprendizagem, alicerçada no pensamento de Le Bouterf e Perrenoud. 
O terceiro trabalho, o artigo "Ambientes virtuais de aprendizagem: desafios de uma escola de governo", é fruto de uma pesquisa das autoras Andrea Filatro e Natália Teles da Mota, que serviu de base para tomada de decisão em relação às escolhas tecnológicas para as atividades da ENAP. Essa pesquisa daria subsídios à ENAP para definir quais produtos e serviços seriam mais adequados para a escola e apoiaria inclusive a forma de contratação e gestão de contratos destes mesmos produtos e serviços tecnológicos. Para tanto, as autoras elaboraram um diagnóstico da instituição em relação ao grau de maturidade tecnológica em que se encontrava. Além disso, realizaram um trabalho de prospecção, em que delinearam três tipos de cenários: $o$ primeiro, num nível mais baixo de complexidade, com foco em ferramentas; o segundo, num nível intermediário de apropriação tecnológica, com foco em conteúdo; e o terceiro, com foco em atividades, num elevado nível de complexidade tecnológica. As autoras reforçam que:

Independentemente da decisão sobre o cenário a ser adotado, algumas considerações se fazem necessárias à atenção de gestores e tomadores de decisão para que a solução tecnológica adotada possa corresponder, em médio ou longo prazo, às demandas metodológicas, tecnológicas e jurídicas emergentes. (Filatro e Mota, 2013, p. 115).

A ENAP, representada por essas autoras, demonstrou no artigo uma preocupação futura em relação aos caminhos desejados nas formações em EaD. Para isso, utilizou uma base teórica sólida para fundamentar a pesquisa, considerando diversos aspectos tecnológicos e também estratégicos da instituição para a construção de cenários pedagógicos.

O último trabalho selecionado, o artigo "Os suportes de uma comunidade virtual de aprendizagem: uma experiência do Governo do Estado de São Paulo, Brasil”, de Tania Tavares-Silva, Paulo Dias e José Armando Valente, relata a importância de uma Comunidade Virtual de Aprendizagem (CVA), integrada a um curso de Licitação e Gestão de Contratos, em 2012, da Escola de Governo e Administração Pública (EGAP), da Fundação do Desenvolvimento Administrativo (FUNDAP). O desafio era de disponibilizar o curso, antes presencial, de forma massiva para cerca de três mil servidores públicos, e continuar a promover a interação entre eles.

O curso foi realizado no sistema broadcasting, ou seja, utilizava os meios tecnológicos para apenas transmitir informação aos participantes. A CVA foi criada para proporcionar essa interação entre os formadores e os alunos, dando suporte e promovendo momentos de escuta, em que as dúvidas e as sugestões poderiam ser atendidas, além de se criar situações de troca entre todos.

Os autores, atentos às questões pedagógicas sobre aprendizagem, utilizam várias referências, como Pallof e Pratt, sobre Comunidades Virtuais, e Cavellucci, sobre estilos de aprendizagens. Além destes, Valente, um dos autores do artigo, é um construtivista reconhecidamente importante no cenário da educação e das tecnologias no Brasil. Assim, os autores consideram alguns elementos importantes para que a aprendizagem ocorra, e concordam que num modelo broadcasting não há segurança em afirmar se, como e quando ela ocorreu. Portanto, a ideia central foi de criar uma comunidade virtual de aprendizagem como apoio a uma capacitação broadcasting, em que não há possibilidades de interação, para dar espaço e voz aos participantes, por meio de uma mediação pedagógica e tecnológica colaborativa, possibilitando a construção do conhecimento e de aprendizagem significativa. 
Esse trabalho mostrou a importância dada à interação para uma aprendizagem significativa, algo que, mesmo num ambiente de educação massiva e autoinstrucional, deve ser, de alguma forma, proporcionado.

\section{Conclusões}

Atualmente, há um pensamento e um desejo de que o Estado Brasileiro atinja níveis de excelência, assim como o setor privado e, para tanto, haja um esforço contínuo em manter uma estrutura administrativa e operacional competente. Para o alcance desse resultado, EGs foram criadas para que haja servidores públicos cada vez mais preparados para atender os anseios da sociedade com qualidade e eficiência, por meio da educação corporativa governamental.

No mundo corporativo empresarial, essa já é uma prática comum, e existem muitas experiências com $\mathrm{EaD}$ em cursos de capacitação e formação continuada para os empregados, num esforço de ampliar a competitividade. Universidades corporativas foram sendo implantadas nas estruturas de recursos humanos e gestão de pessoas, e cada vez mais a importância do capital intelectual de uma organização é seu principal recurso num mundo globalizado.

Grandes empresas de economia mista, bancos e corporações já utilizam a EaD rotineiramente, de forma sistematizada, e disponível em grandes plataformas. Porém, mesmo diante da importância de capacitar e preparar o maior número de servidores públicos pela esfera governamental, sabe-se que os cursos presenciais ainda têm grande destaque. Esse fato fica evidente com a escassez de trabalhos acadêmicos sobre o tema da EaD relacionada com as EGs, que a revisão realizada apontou.

Os trabalhos selecionados a priori, mesmo respondendo ao filtro "escola de governo", não estabeleciam relação direta com o trabalho efetuado pelas EGs. Não foi encontrado nenhum trabalho específico que visasse à compreensão da $\mathrm{EaD}$ no contexto de educação corporativa governamental, principalmente nas EGs ligadas ao Poder Executivo. A EaD parece ser mais utilizada na esfera federal, onde, hipoteticamente, há mais recursos financeiros e de estrutura. Essa é uma hipótese ainda a ser estudada.

Concluindo, as análises e descrições do material obtido na revisão acadêmica demonstraram a enorme lacuna sobre temas que envolvam EGs no campo educacional, principalmente no que se refere à $\mathrm{EaD}$, e sugere que, diante da grandiosidade do Brasil em relação ao número de servidores públicos, ainda há muito a ser percorrido. Os resultados também dão pistas de que pesquisas devem ser incentivadas e desenvolvidas nas EGs nesse campo, pois estas priorizam resultados concretos de suas formações, com relatórios anuais e sistemáticos, e acabam por não compartilhar as experiências educacionais de forma acadêmica e teórica no que diz respeito às abordagens, metodologias e práticas.

\section{Referências}

Aguiar, W. N. M. (2012) O Ensino à Distância da Escola de Gestão Pública do Estado do Ceará - EGP como estratégia de formação de servidores públicos: uma avaliação de resultados. 131f. - Dissertação - Universidade Federal do Ceará, Programa de Pós-graduação em Avaliação de Políticas Públicas, Fortaleza (CE). 
Alperstedt, C. (2001). Universidades Corporativas: Discussão e Proposta de uma Definição. RAC, (v. 5, n. 3, Set./Dez., pp. 149-165). Retrieved from http://www.scielo.br/pdf/rac/v5n3/v5n3a08.pdf

Bernheim, C. T. e Chauí, M. de S. (2008) Desafios da universidade na sociedade do conhecimento: cinco anos depois da conferência mundial sobre educação superior. (pp. 44) Brasília: UNESCO. Retrieved from http://unesdoc.unesco.org/images/0013/001344/134422por.pdf.

Bittencourt M. A. e Zouain, D. M. (2010) Escolas de Governo e a Profissionalização do Servidor Público: Estudo dos Casos da Escola de Serviço Público do Estado do Amazonas - ESPEA e da Fundação Escola de Serviço Público Municipal de Manaus - FESPM. Revista ADM.MADE, 14(3), 75-94. Retrieved from http://revistaadmmade.estacio.br/index.php/admmade/article/viewFile/\%2083/81

Brasil (2006). Política e as Diretrizes para o Desenvolvimento de Pessoal da administração pública federal direta, autárquica e fundacional - PNDP. Retrieved from http://www.planalto.gov.br/ccivil_03/_Ato20042006/2006/Decreto/D5707.htm

Cassettari, I. S. (2001). Modelo de análise qualitativa aplicado à avaliação de programas de ensino via internet. Dissertação. UFSC. 74 f. Retrieved from https://repositorio.ufsc.br/bitstream/handle/123456789/79543/187409.pdf?seque $\underline{\text { nce }=1}$

Eboli, M. P. (2004). Educação Corporativa no Brasil: Mitos e Verdades. São Paulo: Gente.

Eboli, M. P. (2012) Sistema de educação corporativa e a EAD. In Educação a Distância: o estado da arte. Fredric Lito e Marcos Formiga (org.) v. 2, pp. 189197. São Paulo. Pearson Education Brasil.

Enap (2006) Educação a distância em organizações públicas: mesa-redonda de pesquisa-ação. Tarcilena Polisseni Cotta Nascimento (org). 200p. Retrieved from http://repositorio.enap.gov.br/handle/1/376.

Enap (2013) Rede Nacional de Escolas de Governo. A Rede Nacional de Escolas de Governo: o que é, trajetória. propósitos e desafios para seu fortalecimento. Brasília. Documento. Retrieved from http://repositorio.enap.gov.br/handle/1/1297.

Filatro, A. e Mota, N. T. (2013). Ambientes virtuais de aprendizagem: desafios de uma escola de governo. Virtual Learning Environment: challenges for a School of Public Service pp. 109-123. Retrieved from http://antigo.enap.gov.br/index.php?option=com_docman\&task=doc_view\&gid $=3903$

Fleury, M. T. L. e Fleury, A. (2001) Construindo o Conceito de Competência. RAC. Edição Especial, p. 183-196.

Games, L. A. (2012). Estruturação de cursos em EAD. In Educação a Distância: o estado da arte. Fredric Lito \& Marcos Formiga (org.) v. 2, pp. 75- 82. São Paulo. Pearson Education Brasil.

Kerr do Amaral, H. (setembro, 2004). Escolas de Governo e Universidade: parceria estratégica para aumentar a capacidade de governo. Palestra proferida na 
Conferência Brasil e União Europeia Ampliada. Universidade Federal do Rio de Janeiro. Retrieved from ww.brasiluniaoeuropeia.ufrj.br/pt/papers/index.php

Le Boterf, G. (1994). De la Compétence: essai sur un attracteur étrange. Paris: Les Éditions d'Organisation.

Le Boterf, G. (2003). Desenvolvendo a competência dos profissionais. São Paulo: Artmed: Bookman.

Le Boterf, G. (2006). Avaliar a Competência de um Profissional: três dimensões a explorar. Reflexão RH, Lisboa-Portugal, 1(1), 60-63. Retrieved from http://www.guyleboterfconseil.com/Article\%20evaluation\%20version\%20direct e\%20Pessoal.pdf.

Lévy, P. A. (2003) Inteligência Coletiva: por uma antropologia do ciberespaço. ( $\left.4^{\mathrm{a}} \mathrm{ed}.\right)$. São Paulo: Loyola.

Oliveira, S. M. (2016) Acessibilidade e usabilidade em curso online: um desafio para as escolas de governo. 125 f., il. Dissertação (Mestrado em Educação) Universidade de Brasília, Brasília. Retrieved from http://repositorio.unb.br/handle/10482/20761

Pacheco, R. S. (2002) Escolas de Governo como centros de excelência em gestão pública: a perspectiva da ENAP - Brasil. In: Revista do Serviço Público/Fundação Escola Nacional de Administração Pública. V. 53, n. 1 jan/mar. 2002. Brasília: ENAP. Retrieved from https://revista.enap.gov.br/index.php/RSP/article/view/280

Perrenoud, P. (2000) Dez novas competências para ensinar. Porto Alegre: Artmed.

Perrenoud, P. (2002). Construir as competências desde a escola. Trad. Bruno Charles Magne. Porto Alegre: ARTMED.

Data de recepção: $25 / 08 / 2018$

Data da revisão: $27 / 12 / 2018$

Data do aceite: $30 / 12 / 2018$ 
